\title{
Prevalence of Post-traumatic Stress Disorder among the General Population of Karachi during COVID-19 Pandemic and its Associated Factors
}

\author{
Dua Ahmed Ali*1, Iqra Ahmed Ali $^{2}$, Karishma Sakharani ${ }^{3}$, Neha Rohra ${ }^{3}$
}

\begin{abstract}
Objective: Coronavirus pandemic has spread globally. It has affected people mentally and economically. These types of pandemics often lead to post-traumatic stress traumatic syndrome among people. Research data is needed to know the PTSD due to the coronavirus pandemic among the general population.

Materials and methods: This study is cross-sectional. Data was collected in 3 days from the general population of Karachi through an online questionnaire regarding age, gender, education, profession, precautionary measures, awareness related to COVID, satisfaction related to COVID, Health information awareness. IESR scale was used to assess post-traumatic stress syndrome. $A$ total of $24 I$ respondents were involved.

Results: Moreover, II.2\% had partial PTSD, 4. I\% had PTSD and 34.9\% had PTSD high enough to suppress the immune system. Among the respondents majority belong to age group 20 to 30, female, student, undergraduate, were aware of COVID, tested positive for COVID, knew someone tested positive for COVID, applied precautionary measures, avoided going out, worried about your family members getting COVID, satisfied with health information available and were aware of health information available. Age group 20 to 30, Male gender, matric education level, housewives, tested positive for COVID, applying precautionary measures, applying social distancing, having present physical symptoms, worrying about your family members getting COVID, was associated with high IESR score and PTSD $(P<0.05)$. Awareness related to COVID-19 and avoiding going out was associated with low IESR scores and were protective factors related to PTSD $(P<0.05)$. Tested positive for COVID, presence of past physical symptoms, satisfaction with health information available, and awareness of health information available were not significantly associated with IESR score and PTSD $(P>0.05)$

Conclusion: During the outbreak of the coronavirus pandemic more than half of the respondents reported partial to severe PTSD. Age group 20 to 30, Male gender, matric education level, housewives, tested positive for COVID, applying precautionary measures, applying social distancing, having present physical symptoms of COVID, worrying about your family members getting COVID are the vulnerable groups which need urgent attention related to PTSD. Awareness related to COVID-19 and avoiding going out are protective factors related to PTSD hence these factors can be considered by higher authorities to make psychological policies.
\end{abstract}

Keywords: Post-traumatic stress syndrome, COVID-19, psychological Interventions, Coronavirus pandemic, IESR scale, vulnerable groups

(c) (i) (2)

DOI: https://doi.org/l0.3329/jom.v23il.57935 Copyright: (C) 2022 Ali DA. This is an open access article published under the Creative Commons Attribution-NonCommercial-NoDerivatives 4.0 International License, which permits use, distribution and reproduction in any medium, provided the original work is properly cited, is not changed in any way and it is not used for commercial purposes.

Received: 09 September, 202I;

Accepted: 12 November, 2021

1. Dow medical college

2. Liaquat University of medical and health sciences

3. Jinnah Sindh medical university

*Corresponding author: Dua Ahmed Ali, Dow Medical College, Karachi, Email: dua.noorani17@dmc.duhs.edu.pk

\section{Introduction}

COVID-19 also known as coronavirus disease first occurred in Wuhan, China, and has spread globally. It is a contagious disease and has been declared an emergency by the world health organization. ${ }^{1}$ As the coronavirus pandemic is 
spreading unpredictably, it led to anxiety and stress among the general population as it is a natural consequence due to pandemic, stated by the world health organization. ${ }^{2}$ As information related to the coronavirus pandemic is easily available through online sources, it has created anxiety and stress among the general population which in the future can be more dangerous than the virus itself. ${ }^{3}$

Previous researchers also state that mental health status is heavily affected by this kind of pandemic hence it is important to determine how does coronavirus pandemic has affected the mental health of people. ${ }^{4,5}$ The previous outbreak has reported that this kind of pandemic causes anxiety, stress, irritability, confusion, and insomnia. Post-traumatic stress disorder has been previously reported by researchers as an immediate effect due to this kind of pandemic. ${ }^{6-8}$

This research is used to find the psychological impact due to the covid-19 pandemic. Impact of event scale IESR is used to find post-traumatic stress disorder among the general population. It is necessary to find how much does COVID19 has affected people psychologically and has led to PTSD disorder among the general population. This research aims to find the vulnerable group more likely to develop PTSD due to the coronavirus pandemic so that immediate actions can be taken by higher authorities in reducing the psychological impact due to COVID-19. Moreover, this research will help the government to make psychological policies to overcome PTSD disorder.

\section{Material and methods}

A cross-sectional survey was conducted. The sample size comprised 241 respondents and the sample consisted of the public belonging to different education levels and professions. Google forms were used to make the questionnaire. Social media was used to spread the questionnaire. The crosssectional survey was conducted to determine post-traumatic disorder among the general population of Karachi during an epidemic of COVID-19 by using an online questionnaire. Respondents completed the questionnaire in English and consent was taken from all the participants. The collection of data was completed in three days: from 2020/04/01 to 2020/05/ 03 . Respondents participation was voluntary, and they could withdraw at any time. Consent was taken from all the participants and personal information was not taken to maintain confidentiality. This research does not include any clinical trials hence Institutional review board permission was not required. Impact of event scale- Revised scale (IESR) was used to assess post-traumatic stress syndrome ${ }^{[9]}$. The IES-R is a 22-item self-report measure (for DSM-IV) that assesses subjective distress caused by traumatic events. Items are rated on a 5-point scale ranging from 0 ("not at all") to 4 ("extremely"). The IES-R yields a total score (ranging from 0 to 88 ) and subscale scores can also be calculated for the Intrusion. Table 1 shows the interpretation of the IESR scale which consisted of 22 questions while Table 3 shows questions asked in the survey.
Table 1 : Shows IESR interpretation

\begin{tabular}{ll}
\hline IESR score & Interpretation \\
\hline 24 or more & $\begin{array}{l}\text { PTSD is a clinical concern and patients } \\
\text { have half PTSD } \\
\text { this represents the best cutoff for a } \\
\text { probable diagnose of PTSD } \\
\text { this is high enough to suppress your } \\
\text { immune system }\end{array}$ \\
\hline
\end{tabular}

Table 2 : Questions asked in the survey

\begin{tabular}{|c|c|}
\hline Questions & Additional information \\
\hline Demographic data & $\begin{array}{l}\text { age, gender, profession, } \\
\text { education level }\end{array}$ \\
\hline Presence of physical & In past 14 days and present \\
\hline symptoms & Symptoms \\
\hline $\begin{array}{l}\text { Knowledge and concern } \\
\text { about COVID-19 }\end{array}$ & $\begin{array}{l}\text { Awareness, concern, and } \\
\text { satisfaction }\end{array}$ \\
\hline Precautionary measures & $\begin{array}{l}\text { whether they took } \\
\text { precautionary }\end{array}$ \\
\hline or not? & $\begin{array}{l}\text { measures or not? type of } \\
\text { precautionary measures they } \\
\text { applied? most, hours spent at } \\
\text { home.? }\end{array}$ \\
\hline Mental health status & poor or good \\
\hline Testing for COVID-19 & $\begin{array}{l}\text { are they tested for COVID- } 19 \text { or } \\
\text { not? knew someone tested for } \\
\text { COVID-19? }\end{array}$ \\
\hline
\end{tabular}

\section{Data Analysis}

Descriptive statistics were calculated for sociodemographic variables, knowledge, and concern related to COVID variables, precautionary measures, Physical symptoms, and health information variables. The mean and standard deviation of the IESR scale were also calculated. Linear regression and Chisquare test were used to assess the association between sociodemographic characteristics, additional health information, health information satisfaction, physical symptoms, knowledge, and concern related to COVID, precautionary measures, and the IESR scale. All tests were two-tailed, with a significance level of $\mathrm{P}<0.05$. Statistical analysis was performed using SPSS Statistic 21.0 (IBM SPSS Statistics New York USA).

\section{Results}

A total of 241 respondents participated. Among them 11.2\% had partial PTSD, 4.1\% had PTSD and 34.9\% had PTSD high enough to suppress immune system. (Table 3) Mean IESR score was 28.3568. (Table 4) Moreover, $19.1 \%$ belong to the age group $<20,69.3 \%$ belong to the $20-30$ age group and $11.6 \%$ belong to the age group $>30.77 .6 \%$ were female while $22.4 \%$ were male. $1.2 \%$ of respondents belong to the corporate sector, $1.7 \%$ belong to the government sector, $5.4 \%$ 
belong to the health sector, $2.8 \%$ were housewives, $86.3 \%$ were students and $2.1 \%$ were self-employed. $9.5 \%$ belong to inter education level, $3.7 \%$ did matric, $9.7 \%$ did postgraduation and $77.3 \%$ belong to undergraduate education level. (Table 5) Among the study population $99.2 \%$ were aware of COVID-19, $0.8 \%$ were tested positive for SARSCoV-2, 29.5\% knew someone tested positive for COVID-19, $97.5 \%$ applied precautionary measures, $47.3 \%$ avoided going out, $10.81 \%$ used hand sanitizer, $36 \%$ did social distancing, $5.4 \%$ wore masks.(Table 6) Past physical symptoms of COVID-19 were present in $2.9 \%, 2.9 \%$ had present physical symptoms of COVID-19, 88.8\% were worried of their family members getting COVID-19, 92.1\% were aware of health information available and $85.1 \%$ were satisfied with the health information available. (Table 7) Furthermore, Table 5,6 and 7 shows age group $20-30(\mathrm{P}=0.001, \mathrm{~B}=15.208,95 \% \mathrm{CI}=25.745$ to 32.158), $\operatorname{Male}(\mathrm{P}=0.121, \mathrm{~B}=15.96,95 \% \mathrm{CI}=21.754$ to 33.467$)$, matric education level $(\mathrm{P}=0.003, \mathrm{~B}=5.694,95 \% \mathrm{CI}=30.000$ to $75.110)$, Housewives $(\mathrm{P}=0.01, \mathrm{~B}=14.834,95 \% \mathrm{CI}=8.459$ to 59.540) were more likely to get PTSD. Table 6 shows Respondents who were aware of COVID-19 ( $\mathrm{P}=0.033$, $\mathrm{B}=13.302,95 \% \mathrm{CI}=-234.536$ to 324.536$)$ and knew someone who was tested positive for $\operatorname{COVID}(\mathrm{P}=0.015, \mathrm{~B}=10.871,95 \%$ $\mathrm{CI}=21.060$ to 31.418 ) were less likely to get PTSD. Table 6 shows avoiding going out $(\mathrm{P}=0.033, \mathrm{~B}=9.2,95 \% \mathrm{CI}=18.750$ to 35.477$)$ was associated with a low IESR score while applying social distancing $(\mathrm{P}=0.033, \mathrm{~B}=12,95 \% \mathrm{CI}=33.677$ to 42.989) was associated with a high IESR score and PTSD. Table 7 shows Patients having present physical symptoms $(\mathrm{P}=0.022, \mathrm{~B}=12.977,95 \% \mathrm{CI}=25.598$ to 31.145$)$ were more likely to develop PTSD. Table 7 also shows worrying about family members getting COVID-19 $(\mathrm{P}=0.028, \mathrm{~B}=14.085,95 \%$ $\mathrm{CI}=26.486$ to 32.345 ) was associated with a High IESR score. Tested positive for COVID, presence of past physical symptoms, satisfaction with health information available, and awareness of health information available were not significantly associated with IESR score and PTSD $(\mathrm{P}>0.05)$.

Table-3: Shows percentages of different stages of PTSD reported by respondents

\begin{tabular}{lc}
\hline IESR Interpretation & $\mathrm{N} \%$ \\
\hline Partial PTSD & 11.2 \\
Full PTSD & 4.1 \\
High enough to suppress the immune system & 34.9 \\
\hline
\end{tabular}

Table - 4 : Shows mean and standard deviation of IESR scores

\begin{tabular}{lcc}
\hline Mean & N & Std. Deviation \\
\hline 28.3568 & 241 & 21.41546 \\
\hline
\end{tabular}

Table- 5 : Shows linear regression and Chi-square test between demographic data and IESR scores.

\begin{tabular}{|c|c|c|c|c|c|c|c|}
\hline Variables & & $\mathrm{N} \%$ & $95 \%$ Confidence Interval & Beta coefficient & $\mathrm{R}^{2}$ & $\mathrm{AR}^{2}$ & P-value \\
\hline \multirow[t]{3}{*}{ Age } & $<20$ & 19.1 & 20.571 to 34.341 & 8.470 & 0.049 & 0.045 & 0.001 \\
\hline & $20-30$ & 69.3 & 25.745 to 32.158 & 15.208 & & & \\
\hline & $>30$ & 11.6 & 17.9313 to 34.640 & 11.814 & & & \\
\hline \multirow[t]{2}{*}{ Gender } & female & 77.6 & 25.476 to 31.667 & 12.917 & 0.09 & 0.005 & 0.121 \\
\hline & Male & 22.4 & 21.754 to 33.467 & 15.96 & & & \\
\hline \multirow[t]{6}{*}{ Profession } & Corporate sector & 1.2 & -16.909 to 40.243 & 11.6 & 0.03 & 0.031 & 0.01 \\
\hline & Government sector & 1.7 & -22.168 to 64.168 & 12.648 & & & \\
\hline & Health sector & 5.4 & 11.461 to 40.538 & 13.696 & & & \\
\hline & Housewives & 2.9 & 8.459 to 59.540 & 14.834 & & & \\
\hline & Students & 86.3 & 26.068 to 31.873 & 15.792 & & & \\
\hline & Self-employed & 2.1 & 7.320 to 21.079 & 16.84 & & & \\
\hline \multirow[t]{4}{*}{ Education } & Inter & 9.5 & 18.274 to 37.986 & 8.574 & 0.024 & 0.020 & 0.003 \\
\hline & matric & 3.7 & 30.000 to 75.110 & 5.694 & & & \\
\hline & postgraduate & 9.5 & 14.413 to 30.890 & 11.454 & & & \\
\hline & undergraduate & 77.3 & 25.1101 to 31.155 & 14.334 & & & \\
\hline
\end{tabular}


Table 6 : Linear regression and Chi-square test between of awareness of COVID-19, testing of COVID-19, precautionary measures of COVID-19 and IESR scores

\begin{tabular}{llclcccc}
\hline Variable & $\mathrm{N} \%$ & 95\% Confidence Interval & Beta coefficient & $\mathrm{R}^{2}$ & $\mathrm{AR}^{2}$ & P-value & \\
\hline Aware of & Yes & 99.2 & -234.536 to 324.536 & 13.302 & 0.016 & 0.013 & 0.033 \\
COVID & No & 0.8 & 25.496 to 30.938 & 29 & & & \\
Tested positive & Yes & 0.8 & 25.629 to 31.107 & 12.33 & 0.000 & -0.003 & 0.876 \\
for COVID & No & 99.2 & -61.943 to 115.943 & 13.482 & & & \\
Knew someone & Yes & 29.5 & 21.0607 to 31.418 & 10.871 & 0.021 & 0.017 & 0.015 \\
positive for COVID & No & 70.5 & 26.0281 to 32.454 & 14.775 & & & \\
Application of & Yes & 97.5 & 25.729 to 31.232 & 13.457 & 0.000 & -0.004 & 0.897 \\
precautionary & No & 2.5 & -0.6484 to 47.648 & 14.2 & & & \\
measures & & & & & & & \\
Precautionary & Avoid going out & 47.3 & 18.750 to 25.477 & 9.2 & 0.004 & 0.006 & 0.033 \\
measures & Hand sanitizer & 10.81 & 17.361 to 37.331 & 10.6 & & & \\
& Social distancing & 36 & 33.677 to 42.989 & 12 & & & \\
& Wearing masks & 5.4 & 12.775 to 28.147 & 13.4 & & & \\
\hline
\end{tabular}

Table 7 : Linear regression and Chi-square test between the presence of physical symptoms, awareness of health information available, satisfaction related to health information available, and IESR scores

\begin{tabular}{|c|c|c|c|c|c|c|c|}
\hline Variables & $\mathrm{N} \%$ & 95\% Confidence Interval & Beta coefficient & $\mathrm{R}^{2}$ & $\mathrm{AR}^{2}$ & P-value & \\
\hline Presence of past & yes & 2.9 & 25.820 to 31.359 & 13.482 & 0.000 & -0.004 & 0.931 \\
\hline physical symptoms & no & 91.7 & -0.581 to 39.914 & 13.111 & & & \\
\hline Worried about & yes & 88.8 & 26.486 to 32.345 & 14.085 & 0.017 & 0.014 & 0.028 \\
\hline $\begin{array}{l}\text { family members } \\
\text { getting COVID }\end{array}$ & no & 11.2 & 13.346 to 26.579 & 9 & & & \\
\hline Satisfied with the & yes & 85.1 & 26.665 to 32.604 & 13.470 & 0.000 & -0.004 & 1.000 \\
\hline $\begin{array}{l}\text { health information } \\
\text { available }\end{array}$ & no & 14.9 & 15.210 to 27.289 & 13.471 & & & \\
\hline Presence of present & yes & 2.9 & 10.892 to 44.821 & 12.977 & 0.019 & 0.015 & 0.022 \\
\hline physical symptoms & no & 97.1 & 25.598 to 31.145 & 19.572 & & & \\
\hline Aware of health & yes & 92.1 & 25.401 to 31.165 & 13.674 & 0.003 & 0.000 & 0.330 \\
\hline information available & no & 7.9 & 21.079 to 37.341 & 10.8 & & & \\
\hline
\end{tabular}

\section{Discussion}

Researchers collected the responses from respondents in 3 days and the following were the results: $11.2 \%$ had partial PTSD, $4.1 \%$ had PTSD and $34.9 \%$ had PTSD high enough to suppress the immune system. Most of the respondents belong to age group 20 to 30 , female, student, undergraduate, were aware of COVID, tested positive for COVID, knew someone tested positive for COVID, applied precautionary measures, avoided going out, worried of your family members getting COVID, satisfies with health information available and were aware of health information available.

Research conducted in Karachi shows age was not significantly associated with stress ${ }^{10}$ while this research shows the 20-30 age group was highly prevalent toward PTSD. The female gender is more likely to get affected psychologically during these pandemics, stated by previous 
researchers. ${ }^{11-12}$ while research conducted in Karachi showed gender was not associated with anxiety and psychological impact due to pandemic. ${ }^{13}$ This research shows Male gender are at high risk of developing post-traumatic stress disorder. In this study, PTSD was positively associated with the 20 to 30 age group, Male gender, matric education level, and housewives. These vulnerable groups need urgent attention and counseling regarding PTSD. Secondly, Knowledge and concern related to COVID-19 was a protective factor related to PTSD. Accurate health information should be delivered to people by social media or other electronic means. Previous researches indicate the presence of physical symptoms related to COVID is associated with high anxiety; this research shows similar results. ${ }^{14}$ PTSD is positively associated with the presence of physical symptoms hence it is suggested that people coming to clinicians with physical symptoms should be provided with psychological counseling as PTSD is highly associated with the presence of physical symptoms related to COVID-19.

Thirdly this study indicates, showing concern related to COVID-19 is positively associated with PTSD hence online activities or different meditation activities should be introduced to reduce the occurrence of PTSD hence which can relax the public. Furthermore, other researchers found that applying precautionary measures was associated with Less psychological impact ${ }^{15}$ this study contradicts with it. This research shows applying precautionary measures is associated with PTSD. Avoiding going out is a protective factor related to PTSD while maintaining social distancing is a risk factor related to PTSD Hence people should be recommended to stay at home and avoid going out. The previous study indicates satisfaction with health information available is a protective factor regarding psychological impact $^{16}$ wherever this study contradicts with it. This research shows satisfaction related to health information available is associated with PTSD.

Our study has several limitations. Firstly, because of confidentiality reasons, researchers did not collect any information related to biodata hence researchers will not be able to inform their participants about their psychological impact and PTSD state. Our research still provides enough data for identifying the vulnerable groups during the pandemic that needs urgent attention and will help the government to make psychological policies to overcome the PTSD disorder.

\section{Conclusion}

During the outbreak of the coronavirus pandemic more than half of the respondents reported partial to severe PTSD. Age group 20 to 30, Male gender, matric education level, housewives, tested positive for COVID, applying precautionary measures, applying social distancing, having present physical symptoms of COVID, worrying about your family members getting COVID are the vulnerable groups which need urgent attention related to PTSD. Awareness related to COVID-19 and avoiding going out are protective factors related to PTSD hence these factors can be considered by higher authorities to make psychological policies.

\section{References:}

1. World Health Organization. Novel coronavirus (2019-nCoV) situation reports. (2020). Accessed: July 3, 2020: https:// www.who.int/docs/default-source/coronaviruse/situationreports/20200607-covid-19-sitrep-139.pdf?sfvrsn $=79 \mathrm{dc} 6 \mathrm{~d} . .$. .

2 Lai CC, Shih TP, Ko WC, Tang HJ, Hsueh PR. Severe acute respiratory syndrome coronavirus 2 (SARS-CoV-2) and coronavirus disease-2019 (COVID-19): The epidemic and the challenges. Int J Antimicrob Agents. 2020 Mar;55(3):105924. doi: 10.1016/j.ijantimicag.2020.105924. Epub 2020 Feb 17. PMID: 32081636; PMCID: PMC7127800.

3. Depoux A, Martin S, Karafillakis E, Preet R, Wilder-Smith A, Larson $\mathrm{H}$. The pandemic of social media panic travels faster than the COVID-19 outbreak. J Travel Med. 2020 May 18;27(3):taaa031. doi: 10.1093/jtm/taaa031. PMID: 32125413; PMCID: PMC7107516.

4. K., H.C. The psychological impact of SARS(2004): a matter of heart and mind. CMAJ. ;170:811-812.

5. Wu P, Fang Y, Guan Z, Fan B, Kong J, Yao Z, Liu X, Fuller CJ, Susser E, Lu J, Hoven CW. The psychological impact of the SARS epidemic on hospital employees in China: exposure, risk perception, and altruistic acceptance of risk. Can J Psychiatry. 2009 May;54(5):302-11. doi: 10.1177/ 070674370905400504. PMID: 19497162; PMCID: PMC3780353.

6. Shigemura J, Ursano RJ, Morganstein JC, Kurosawa M, Benedek DM. Public responses to the novel 2019 coronavirus (2019-nCoV) in Japan: Mental health consequences and target populations. Psychiatry Clin Neurosci. 2020 Apr;74(4):281282. doi: 10.1111/pcn.12988. Epub 2020 Feb 23. PMID: 32034840 ; PMCID: PMC7168047.

7. Lima CKT, Carvalho PMM, Lima IAAS, Nunes JVAO, Saraiva JS, de Souza RI, da Silva CGL, Neto MLR. The emotional impact of Coronavirus 2019-nCoV (new Coronavirus disease). Psychiatry Res. 2020 May;287:112915. doi: 10.1016/j.psychres.2020.112915. Epub 2020 Mar 12. PMID: 32199182; PMCID: PMC7195292. 
8. Zandifar A, Badrfam R. Iranian mental health during the COVID-19 epidemic. Asian J Psychiatr. 2020 Jun;51:101990. doi: 10.1016/j.ajp.2020.101990. Epub 2020 Mar 4. PMID: 32163908 ; PMCID: PMC7128485.

9. Lim GY, Tam WW, Lu Y, Ho CS, Zhang MW, Ho RC. Prevalence of Depression in the Community from 30 Countries between 1994 and 2014. Sci Rep. 2018 Feb 12;8(1):2861. doi: 10.1038/s41598-018-21243-x. PMID: 29434331 ; PMCID: PMC5809481.

10. Almeida M, Shrestha AD, Stojanac D, Miller LJ. The impact of the COVID-19 pandemic on women's mental health. Arch Womens Ment Health. 2020 Dec;23(6):741-748. doi: 10.1007/s00737-020-01092-2. Epub 2020 Dec 1. PMID: 33263142 ; PMCID: PMC7707813.

11. Weiss, \& Marmar, 1996. Impact of Event Scale - Revised (IES-R) for DSM-IV, PTSD: National Center for PTSD

12. Almeida M, Shrestha AD, Stojanac D, Miller LJ. The impact of the COVID-19 pandemic on women's mental health. Arch Womens Ment Health. 2020 Dec;23(6):741-748. doi: 10.1007/s00737-020-01092-2. Epub 2020 Dec 1. PMID: 33263142 ; PMCID: PMC7707813.

13. Kumar D, Saghir T, Ali G, Yasin U, Furnaz S, Karim M, Hussain M, Kumari R, Bai R, Kumar H. Psychosocial Impact of COVID-19 on Healthcare Workers at a Tertiary Care
Cardiac Center of Karachi Pakistan. J Occup Environ Med. 2021 Feb 1;63(2):e59-e62. doi: 10.1097/JOM.0000000 000002094 . PMID: 33234873; PMCID: PMC7864597.

14. Wang C, Pan R, Wan X, Tan Y, Xu L, Ho CS, Ho RC. Immediate Psychological Responses and Associated Factors during the Initial Stage of the 2019 Coronavirus Disease (COVID-19) Epidemic among the General Population in China. Int J Environ Res Public Health. 2020 Mar 6;17(5):1729. doi: 10.3390/ijerph17051729. PMID: 32155789; PMCID: PMC7084952.

15. Leung GM, Lam TH, Ho LM, Ho SY, Chan BH, Wong IO, Hedley AJ. The impact of community psychological responses on outbreak control for severe acute respiratory syndrome in Hong Kong. J Epidemiol Community Health. 2003 Nov;57(11):857-63. doi: 10.1136/jech.57.11.857. Erratum in: J Epidemiol Community Health. 2003 Dec;57(12):995. PMID: 14600110; PMCID: PMC1732323.

16. Wang C, Pan R, Wan X, Tan Y, Xu L, Ho CS, Ho RC. Immediate Psychological Responses and Associated Factors during the Initial Stage of the 2019 Coronavirus Disease (COVID-19) Epidemic among the General Population in China. Int J Environ Res Public Health. 2020 Mar 6;17(5):1729. doi: 10.3390/ijerph17051729. PMID: 32155789; PMCID: PMC7084952. 